\title{
Bir Yer, Bir Kadın, Bir Öykü: Meryem Filminde Toplumsal Cinsiyetin Kültürel İnşası
}

SELÇUK ILETIŞIM

DERGISI 2021;

14(2): 657-673

doi: $10.18094 /$ JOSC.818314

\section{Sema Zafer Sümer}

\section{ÖZ}

Gelenek, görenek ve dini inanç kodlarıyla beslenen ve yapılanan ataerkil toplum, Anadolu'da kadını her yönden kuşatan ve sınırlayan bir sistemin içine hapseder. Kadının üretim sürecine katılım ve dış dünyaya açılımı bilinçli bir şekilde engellenir. Geçmişe dayalı doğal bir süreklilikle beslenen bu hiyerarşik sistem içinde toplumun kadına yüklediği taze gelinlik ve kaynanalık önemli rollerdir. Gerçek yaşam öyküsünden yola çıkılarak senaryolaştırılan Meryem filmi kadının toplumdaki yerini, eğitim durumunu, cinselliğini, özgüvenini, "kızkardeşlik" (sisterhood) yoksunluğunu ve ruhunun derinliklerinde yaşadığı gel gitleri anlatan önemli filmlerden bir tanesidir. Amaçlı örneklem yöntemi ile araştırmaya dahil edilen bu filmde Anadolu kırsalında, Beyşehir'de adetler ve diyalog ile biçimlenen kadınlık durumları ve hiyerarşiyi onaylayan atasoylu evlilik sistemi irdelenerek, içinde yaşadığımız toplumun kadın ve erkeğe yüklediği rollere dikkat çekilecektir. Filmin konusu sıradan insanların sıradan öykülerinden birisi gibi gözükse de, Meryem'in yaşadıkları Anadolu'da yüzlerce yıldır benzerlerinin yaşandığı, bugünde acımasızca yaşanmaya devam eden dramlardan sadece bir tanesidir. Bu makalede, böylesi bir sistem içerisinde kadınların kadın olarak var olabilmesi ve var olmanın dayanılmaz zorluğu film çözümleme yöntemlerinden biri olan feminist çözümleme tekniği kullanılarak bulgulanmıştır.

Anahtar Sözcükler: Kadın, Toplumsal Cinsiyet, Kültür, Meryem Filmi, Feminist Film Eleştirisi

\author{
SEMA ZAFER SÜMER \\ Dr. Öğretim Üyesi \\ Selçuk Üniversitesi \\ szsumer@selcuk.edu.tr \\ ORCID ID: 0000-0003-3125-0582
}

SELÇUK ILETIŞIM DERGISI 2021; 14(2): 657-673

doi: 10.18094/ JOSC.818314

Geliş Tarihi: 30.10.2020 Kabul Tarihi: 14.02.2021 Yayın Tarihi: 25.04.2021 


\title{
A Place, A Woman, A Story: The \\ Cultural Reconstruction of Gender in \\ The Movie Meryem
}

JOURNAL OF SELÇUK

COMMUNICATION 2021;

$14(2): 657-673$

doi: 10.18094/ JOSC.818314

[\$]

SELLFIIX

ILETISTM

\section{Sema Zafer Sümer}

\begin{abstract}
In Anatolia, many of whose areas constructed with tradition, custom, and religious belief, patriarchal principles imprison women in a limited life that prevents them from participating in relations of production and establishing environmental communication. In this hierarchical system, which is nourished by a natural continuity based on the past; the women seeking their place within society socialized into roles such as fresh bride, young woman, daughter-in-law, sister-in-law and mother-in-law. These are the important roles that shape their way of living. In this study, the movie Meryem based on a true story of a woman from Beyşehir is taken into consideration as a successful example in the context of gender. In the selected film, we will examine the roles of the society we live in and the roles that women held in the Anatolian countryside, in Beyşehir, by examining the feminine situations shaped by customs and dialogue and the patriarchal marriage system that approves the hierarchy. Though the theme of the film seems to be one of the ordinary stories of the ordinary people, it is not only one of the stories that Meryem has lived but also it is the hurtful drama that has been lived for hundreds of years in Anatolia. The purpose of this study is to show how women can exist as women in such a system and unbearable difficulty of existence as women. The film has been evaluated in the light of feminist film criticism.
\end{abstract}

Keywords: Woman, Gender, Culture, The Movie Meryem, Feminist Film Criticism

\author{
SEMA ZAFER SÜMER \\ Asst. Prof. \\ Selçuk University \\ szsumer@selcuk.edu.tr \\ ORCID ID: 0000-0003-3125-0582 \\ JOURNAL OF SELÇUK COMMUNICATION 2021; 14(2): 657-673 \\ doi: 10.18094/ JOSC.818314
}




\section{GiRiş}

Bir sanat eseri ve kültür ürünü olarak film; dışavurumu, söylemi ve içeriği ile toplumu diğer disiplinlerden daha fazla gözler önüne serme gücüne sahiptir. Sinemayı toplumsal ilişki düzlemini kurgulayan önemli bir iletişim aracı olarak değerlendiren Louis Althusser'e göre "Asında kameranın kaydettiği, egemen ideolojinin belirsiz, formüle edilmemiş, teorize edilmemiş, düşünülmemiş dünyasıdır. Sinema dünyanın kendi kendisiyle iletişim kurduğu dillerden bir tanesidir" (Büker \& Topçu, 2010, s. 104). Henri Lefebvre'ye göre ise, "Bu sanatsal üretimden bize geçen şey, o dünyanın ideolojisinin gerçekliğinin açıkığıyla ortaya konulmasıdır; ideolojiden anlaşılması gereken de gündelik hayat içerisindeki tüm yapıp etmelerimizdir" (2007, s. 39). Böylelikle gündelik olanın toplumsal yapıyı çözümleyecek unsurları içeren bir alan olduğuna dikkat çeken yazar; toplumun kültürel ve zihinsel haritasında yeniden üretilen ilişki biçimlerinin geleneksel algılarımızda nası bir değişim yarattığına veya yaratamadığına vurgu yapar. Günlük yaşamın merkeze alınmasındaki en önemli etken kültürel ve toplumsal normların uygulamada neye dönüştüğü ve nasıl algılandığına dair verileri görebilmektir.

Bu bağlamda Türkiye'de üretilen filmlerde son yirmi yıllık sürece bakıldığında, gündelik hayat pratiğinin en keskin biçimde şekillendiği sıradan kabul edilen taşrada, sıradan hayatlara yönelen naif hikâyelerin önemli bir yer tuttuğu görülür. Elmacı'ya göre bu sıradan öyküler aslında döneme ait hem bireyi hem de toplumu çözümleyebilecek etkide alt metinler barındırır (2011, s. 162). Sıradan olanın içinde saklanan ve çözümlenmeyi bekleyen bu alt metinlerde "taşra"; yerleşik zihniyetlerin ne olduğunun belirlenmesindeki en önemli ana duraklardan biridir. Artık "taşra", sıradan bir yer değil, tüm ülkeye yayılan bir zihniyet göstergesidir (Elmacı, 2011, s. 166). Bu filmlerden bir tanesi de Atalay Taşdiken'in gerçek yaşam öyküsünden yola çıkarak senaryolaştırdığı ve yönetmenliğini yaptığı 2013 yapımı Meryem filmidir. Beyşehir'de yaşayan yoksul bir aile üzerine odaklanan filmin öyküsü, toplumsal yapının en küçük fakat en etkin birimi olan aileyi egemen ideolojilerin meşrulaştırılıp yeniden üretilmesine olanak sağlayan bir ortam olarak mercek altına alır.

Bu çalışmanın amacı ise taşranın gündelikliğine yönelen Meryem filmi aracılığıyla buradaki hayatın ağır ritmini hem biçimsel hem de içeriksel olarak ele almak ve toplumsal kodlamaları gündelik hayat içerisindeki aktörlerin ilişkileri üzerinden yeniden okuyabilmek; gerek toplumsal cinsiyet gerekse toplumsal bağa ilişkin değişmeyen kadın ile ilgili temel algıları film çözümleme yöntemlerinden biri olan 
feminist çözümleme aracılığı ile bulgulayarak gözler önüne serebilmektir. Sinema, özellikle ataerkil düşünceyi üreten, aktaran bir alan olarak düşünüldüğünde; cinsiyet eşitsizliğinin sinemadaki yansımalarına odaklanan temel argümanları ile feminist film eleştirisinin bu çözümleme sürecinde etkin bir yöntem olacağı açıktır. Kadın deneyiminden yola çıkan ve sinemanın çarpıcı dilinden yararlanarak, toplumsal cinsiyete ve kadın sorunlarına iliş̧in tartışmaları yaygınlaştırmayı hedefleyen feminist yaklaşım eril toplumsallaşmaya ait örüntüler yansıtan biçim özelliklerini bizlere aktararak söz konusu cinsiyetçi yapının filmin söylemsel yapısının içinde istikrarsızlaştııımasını amaçlar. Perdedeki kadın imgelerinin, doğal bir kadınlık durumu olmadığına aksine, ataerkil ideolojiler doğrultusunda kurgulanan filmsel anlatı stratejilerinin inşa ettiği toplumsal kimliklerin bir yansıması olduğuna dikkat çeken feminist sinema kuramı ve eleştirisi, kadının biyolojik, cinsel kimliğinin değil; cinsiyetçi ideolojinin yani toplumsal cinsiyetin tartışılması gerekliliğine vurgu yapar (Belkaya, 2001, s. 195), çünkü sinema, Simelik'in de vurguladığı üzere cinsel ayrım üzerine mitlerin oluşturulduğu, yeniden üretildiği, kültürel bir forumdur (1998, s. 137). Bu yüzden çalışmanın bulgularına geçmeden önce kadın, kültür ve toplumsal cinsiyet iliş̧kisi açıklanacaktır.

\section{KADIN, KÜLTÜR VE TOPLUMSAL CINSIYET}

Her türlü yaşayış ve düşünce birikiminin gelenekle bütünleşerek nesilden nesile aktarıldığı kültür, toplumda geleneksel duyuş ve düşünüş birliği oluşturan en önemli unsurdur. Yeniden inşa süreci içerisinde tüm bu birikimler "sosyal gerçeklik" adı altında normalleştirilir. Her ne kadar birey kendi deneyimi ve yaşanmışlığı ile toplumsal değişime katkı sağlasa da geçmişin etkisinden kurtulamaz. Bugün ve gelecek tüm bu birikimlerle şekillenir. Bayhan'ın da vurguladığı üzere, "Toplumsal cinsiyete atfedilen bütün "anlamlar" ve "simgeler", geçmişin ve şimdinin ruhundan geçerek gelecekteki toplumsal cinsiyet imgesine aktarıı" (Bayhan, 2013, s. 148). İşte bu yüzden kadınların ezilişi tarihsel bir gelişimin ve toplumların kültürel olgularının bir sonucudur. Vehbi Bayhan'ın Beden Sosyolojisi ve Toplumsal Cinsiyet adlı makalesinde toplumsal cinsiyetin sosyal inşası aşağıdaki cümlelerle irdelenir:

"Biyolojik açıdan doğuştan gelen cinsiyet, sosyal bir inşa sürecinden geçerek toplumsal cinsiyete dönüşür. Bireyin sosyal bir varlık olması, bedenin sosyolojik açıdan irdelenmesini gerekli kılar. Beden biyolojik, psikolojik ve sosyolojik boyutlarıyla bir bütündür. Bu gerçeklikler bedenin toplumsal cinsiyet şeklinde üretilmesinde karşılıklı etkileşim içerisindedirler. Ancak, toplum bedenin inşasında başat rol oynar... Beden benlik algısının, kişiliğin ve kimliğin çok önemli bir parçasıdır... Sosyo-biyolojik yaklaşımı temel alan 
biyologlar, genetikçiler ve tıpçılar bedeni kendi doğası ve sınırları olan bir varlık alanı şeklinde tanımlarken sosyolojik yaklaşımı temel alan sosyal bilimciler bedenin toplumsal ve kültürel açıdan tümüyle inşa edildiğini savunurlar. Dolayısıyla beden sosyal bir inşa sürecidir. Toplum içinde cinsiyet kalıpları sosyalleşme sürecinde öğrenilir ve içselleştirilir." (2013, s. 148-149)

Toplumsal cinsiyet (gender) bağlamında tanımlanan bu özellikler doğumundan ölüme kadar bireyi kuşatır. "Toplumsallaşma teorisi, toplumsal cinsiyet oluşumunu, toplumsal normların kazanılması ve içselleştirilmesi olarak görür" diyen Connell'a göre toplumsallaşma aslında toplumsal rollerin az ya da çok içselleştirme sürecidir (1998, s. 256). Bayhan'ın da ifade ettiği üzere "kadın ya da erkek olmak salt ontolojik bir durum değildir; bedenin kadın ya da erkek cinsiyetiyle inşa edilmesinde, toplumun ürettiği kalıp yargılarla oluşturulan toplumsal cinsiyet epistemesi ve aynı zamanda erkek ya da kadın olmanın toplum tarafından üretilen etik boyutu vardır" (2013, s. 163). Nasıl ki "ahlaki beden, maddi doğamızın, anlam ve değerle buluştuğu bağlamdır (Eagleton, 2004, s. 160), tıpkı bunun gibi insani beden de doğa ve kültürün kesişme noktasıdır" (Turner, 1996, s. 178). "Erkeğin toplumsal değerler üzerine konuştuğunu ama kadının varlığıyla bu değerleri temsil ettiğini" söyleyen Sözer (1993, s. 11-12) kadının da toplumsal dizgenin bir parçası olmasına rağmen, cinsiyet olgusunun ön plana çıkarılarak cinsler arasında birinin "öteki"ne dönüştürüldüğü toplumsal zihniyete vurgu yapar.

Cinsiyetin kişileri gruplamak ve farklılaştırmak adına kullanılan birincil ölçütlerden biri olduğunu vurgulayan Güvenç'in aşağıdaki cümleleri derinlikteki düşüncenin algılanması açısından oldukça dikkat çekicidir:

"İsmimiz, işimiz, sesimiz, saçımız, giysilerimiz, tutum ve davranışlarımız, cinsiyetimizi gösteren simgelerdir. Cinsiyet kavramı, dünya üzerindeki bütün insanları, sayıca birbirine eşit iki gruba ayııır. Gruplardan birisine 'erkek' ötekine 'kadın' adı verilir. Toplumlar, 'kadın' ile 'erkek' arasındaki biyolojik farkı o denli abartırlar ki; kadın ve erkek birbirine yabancı iki yaratık haline gelir" (1999, s. 223-224).

Gündelik hayat, kadınlık ve erkeklik rollerinin egemen toplumsal cinsiyet yaklaşımına göre yeniden üretildiği kültürel bir alandır. Kültürel hafızadan beslenen veya kültürel hafızayı besleyen tüm bu mit, ritüel ve efsanelerin toplumda yeniden nasıl tanımlandığını ve ayrıntılara bağlandığını bizlere aktaran Tan'a ait aşă̆ıdaki cümleler bu işlevselliğe vurgu yaparken, köklerin ne kadar derinlerde olduğunu ifade eder: 
"Her toplum kadın ve erkeğe ayrılan rolleri, geleneksel norm ve değerlere dayalı basmakalıp yargılarla haklı göstermeye, kadına ve erkeğe uygun düşen davranışları, göreneksel imgelerle anlatıma ve sağlamlaştırmaya yönelir. Bu durum öylesine uzun süre ve öylesine evrensel olarak sürüp gitmiştir ki sonuçta derine kök salmış toplumsallaşma kalıpları ortaya çıkmıştır" (1979, s. 160).

Benlik algımız bilinçli şekilde yapılanan ve zihinlerimize uyarlanan sayısız kültürel gerçeklik ve inançlar doğrultusunda oluşur. Kadınlara ve erkeklere atfedilen tüm bu özellikler bilişsel, duygusal ve davranışsal yapımızı etkiler. Sosyal inşa süreci içinde normalleştirilen kadın ile ilgili temel algılar, yaşama biçimimizi, algılarımızı, tercihlerimizi ve kullandığımız dili belirler. Toplumun her alanında kadının karşısına çıkan tüm bu beklentiler ve zihinlere kazınan bu düşünceler kadını biçimlendirir ve onu baskılanan ve ideolojik bir göstergeye dönüştürür. İşte bu yüzden, renkten, giyim tarz ve biçimlerimize, modaya kadar bütün sembolik alanlarda toplumsal cinsiyet örüntüsü, toplum tarafından yaratılan ve kodlanan bir öğrenilmiş davranış pratiğidir (Fine, 2011, s. 113). Sonuç olarak, asla "ben" olamayan birey var olma yolculuğunda toplumsal baskının gölgesinde yeniden biçimlenecek, denetlenecek ve yeniden üretilecektir. Toplum tarafından kadın ve erkeğe ait kılınan tüm roller iki cins arasındaki tahakküm ilişkisini güçlendirerek kadını ikincil kılan hiyerarşik yapılanmayı daha da etkin kılacaktır.

Bu nedenle toplumun yapısını, kadın üzerinden okumak mümkündür. Zira kadın, bireyleri biyolojik olarak dünyaya getirdiği gibi, insan tekinin diğer cinsi için de önemli bir ayna hatta onun ruhsal ve kişisel doğumuna da tanıklık eden bir öznedir. Özneler arası biyolojik ilişkinin imkânı veya kırılma noktaları genelde toplumlarda özellikle de kadın aleyhine olarak sorunlu şekilde algılanmaktadır. Dolayısıyla her iki cins için monologdan tutalım da toplumsal dönüşüm ve değişimlere kadar pek çok konunun aydınlatılmasında kadın başat aktördür. Nitekim yapısalcı antropolog Levi Strauss'a göre, "kadının durumunu veya hareketini anlamak, toplumu çözümlemek için en önemli ayırıcı yapısal sınırları anlamaktır" (Köysüren, 2013, s. 60).

Dolayısıyla, bu çalışmada örneklem olarak belirlenen Meryem filminde; Anadolu'daki gelenek ve diyalog ile şekillenen kadınlık halleri ve hiyerarşiyi onaylayan atasoylu evlilik sistemiyle; içinde yaşadığımız toplumun kadın ve erkeğe yüklediği rollere dikkat çekilecek ve kadına atfedilen toplumsal kodların salt metinsel bir okumanın ötesinde farklı değişkenlerle yeniden okuması yapılacaktır. 


\section{YÖNTEM}

Bu çalışmada amaçı̆ı örneklem yöntemi ile araştırmaya dahil edilen Meryem filmi, film çözümleme yöntemlerinden biri olan feminist eleştiri kullanılarak incelenmiştir. Feminist film eleştirisinin ortaya çıkışına Women and Film dergisi öncülük etmiştir. Bu derginin feminist perspektifin sinemaya nasıl uyarlanacağının örneklerini sunması sayesinde, 1960'ların sonlarından itibaren sinemaya ve film türlerine yönelik feminist eleştiri kuramsal çalışmalara katılmıştır. Feminist eleştirinin odak noktası, filmdeki ataerkil iktidarın yansımalarını deşifre etmek olmuştur (Abisel, 1999, s. 35), ancak feminist eleştiri kendi başına bir disiplin değildir sadece psikanalitik, sosyolojik, tarihsel ve göstergebilimsel yaklaşımlardan yararlanıp, değişik yaklaşım ve okulları arasına alarak kadınca bir tepki oluşturmayı amaçlamıştır. Sinemaya yöneltilen feminist eleştiride her kuramcı kendi düşünce yapısı ve bilgi birikimi doğrultusunda bu yaklaşımları kullanarak eleştirilerini ortaya koymaktadır (Süllü, 1988, s. 184-186). Böylece feminist film eleştirisi, sinemada toplumsal cinsiyet rollerine, kadının ve erkeğin rollerine farklı gözlerle bakmamı için bize bir yol gösterir (Güçhan, 2004, s. 2-3). Feminist eleştirmenler sinema perdesinde yansıyan kadın imgelerinin gerçek kadınlara ait olarak değil, erkeğin kadına yönelik bilinçaltı duygu ve düşüncelerinin, arzu ve korkularının temsil edilmesi işlevi içinde yansıma bulduklarını, kadının erkek için temsil ettiği şey olarak sunulmasına aracılık ettiğini kabul etmektedirler (Özden, 2000, s. 164). Feminist film kuram ve eleştirisi de kaynağını buradan alarak sinemanın toplumsal cinsiyeti kurgulama biçimlerine yoğunlaşmaktadır. Bu anlamda feminist film eleştirisi ile sinemada kadının kendi biyolojik cinsel kimliğinin yerine toplumsal olarak kodlanan ve ataerkil ideolojiyi pazarlayan toplumsal cinsiyet olgusu tartışma olanağı bulmaktadır (Timisi, 2011, s. 167).

\section{KADININ INSSAN KIMLiĞínin VE BENLIǦinin PARÇALANIŞI: MERYEM Fími}

Kız Kardeşim Mommo ve Meryem filmleriyle Türk sinemasında yeni bir duyarlılık evreni oluşturmaya çalışan Atalay Taşdiken; kadının konumunu yansıtması, kadın erkek ilişkileri ile biçimlenen dünyanın değiş̧ken yanlarını sergilemesiyle, bizlere kadın imgesi üzerinde yeniden düşünme fırsatı verirken, toplumsal olarak kodlanan birçok olguyu yeniden okuma ve tartışma olanağı sağlar. Filmlerinde bireylerin çevre ve toplumsal oluşumların etkisiyle biçimlenen ve değişen ruh hallerini, iletişim ve iletişimsizliği, sevgi ve varoluş sorunlarını kendi penceresinden vermeye çalışan yönetmen, psiko-sosyal yaklaşımlarla özellikle kadını, yaşadığı çaresizlik ve yalnızlık duvarlarıyla örülü coğrafyasında gözler 
önüne serer. Taşdiken, gerçek bir yaşam öyküsünden uyarladığı Meryem filminin sınırları içinde ele alınan anlatıda, özerklik ve bağımsızlık arzusu ile ikincil konumda olma gerçeği arasındaki gerilimi en yoğun şekliyle hisseden Meryem'in dramını dünyaya sunarken; estetiğin sadece nesnesi konumuna indirgenen kadının, insan kimliğinin ve benliğinin parçalanışına vurgu yapar.

Dünyadaki birçok genç kadının paylaştığı yazgıyı yaşayan Meryem, Anadolu'nun küçük kasabasında, taşrada, küçük yaşta evlendirilen; evlendiği adamla sadece altı gün birlikte olabilen ve kocasının İstanbul'a dönüşüyle gelin geldiği bu evde kayınvalidesi ve kayınpederiyle yaşamaya terk edilen genç bir kadındır. Her şeyin geleneksel yani yerleşik düzende ilerlediği bu evde hayat olağan ve durağandır; asla bozulmayan dokusuyla yaşam, doğanın kendi akışına bırakılmıştır. Meryem'in hayatındaki tek renklilik komşusunun zihinsel engelli oğlu Celil ile paylaşımları; süt sağarken Sarıkız ile kurduğu duygusal bağ ve kayınvalidesi tarafından peynir satması için gönderildiği pazar yerindeki birkaç cümleyle sınırlanan sohbetlerden ibarettir.

Kendi istekleri ve toplumun ondan beklentileri arasında kalmaktan kurtulamayan bu "taze gelin" için yaşadığı ev mutsuzluğun mekanıdır. Meryem'i yok etmek için üzerine yürüyen karşı güçlerin simgesel göstergesidir. Dardır, boğucudur, yok edicidir. Evde kapalı tutulan ve itaat altına alınan salt kadının bedeni değildir. Aynı zamanda kadının iç dünyası da eril söylemle yeniden biçimlendirilerek kontrol altında tutulur. Ataerkil söylemin desteklediği bir tür geleneksellik içinde iffet ve ahlaka uygun kadın zihniyetleri ve bedenleri üretilir ve gelenekler kişinin davranışlarını biçimlendirir (Benedick, 1998, s. 24). "Evli barklı kadınsın, laf söz olur! Kocan duyar", "El âlem ne der?" veya "El âleme ne diyeceğiz?" (Taşdiken, 2013) cümleleri film boyunca sürekli yinelenirken "diğeri için varlık olma" halinin etkileri Meryem üzerinden seyirciye aktarılır. Hayatın canlılı̆ı değil, külfetiyle boğuşan Meryem, toplumsal yapıya eğreti bir şekilde tutunur, kısacası ısmarlama bir kişiliği oynamaya veya temsile zorlanır. Kayınvalidesi için ev işlerini yapan bir hizmetçi; emanetin bekçisi kayınpederi için korunması gereken bir namus; zihinsel engelli Celil'in arkadaşı, görümcesi için işleri kendisinden alan kurtarıcı bir köle, askere gitmeden önce kendisine evlilik teklif eden Murat'ın tutuklu kaldığı sevgilisi, hiç bir zaman varlığından haberdar olmayan, onu bekleten ve asla dönmeyecek bir erkeğin, Mustafa'nın karısı; eve gelen sütçünün göz koyduğu kadın, kısacası sadece bir nesne, hayatın akışına terk edilmiş şairin deyimiyle "sanki hiç yaşamamış gibi ölen"dir. 
Sürekli sabretmesi, beklemesi, sevmesi istenilen Meryem'in filmdeki çığıı̆ı sınırların, sözcüklerin anlamının bittiği yerde başlamaktadır. Annesinin "sabret Meryem... sabır kızım..." (Taşdiken, 2013) cümleleri karşısında "... bana başka bir şey söyle! Neyim ben? Bana kimse sahip çıkmıyor ... Yapamayacağım, beni yanına al anne" (Taşdiken, 2013) cümleleri alçaltıcı ve yıpratıcı baskılara karşı direnç gösterecek dik duruşu kendisinde bulamayan Meryem'in çaresizliğinin ve sessizliğinin söze dönüşmesidir. Fakat ne yazık ki süregelen düzenin mağdurlarından biri olan annesinin de dul bir kadın olarak ne kendisi ne de Meryem için biçimlenmiş ve biçimlendirilmiş bu durumu değiştirecek gücü ve bilinci yoktur. Filmde "Ben ne çektim seni babasız büyütüp, laf söz olmadan everenceye kadar... Koca evine girdin mi bir daha dönüşü yok kızım" (Taşdiken, 2013) cümleleri bir tür muhafaza göreviyle yükümlendirilen bir kadının bu yükü layıkıyla taşıdığı sürece toplumda onay alabileceğini ima eden binlerce yıllık açılımın bir yansımasıdır. Güvensiz, riski göze alamayan bu kadın insan olmanın onurunu, cesaretini ve gururunu hiç bilemeyecek ve diğer bir kadına aktaramayacaktır. Bu bağlamda Köysüren'in de vurguladığı üzere;

"Şerefin bekçisi olan, dogmatik kurallara esir olan kölenin riske girme ihtimali olmadığı gibi, kendini görme fırsatı da olmayacaktır. Dahası kendini hiçbir zaman göremeyen, beden denilen hapishanenin taşıyıcı, kadın cinselliğinin de koruyucusudur. İnsan etten ve kemikten bir robottur, yaşam bir rutindir, ömür yaşanması gereken ritüellerdir. Bu tabloda insan doğmayacak, bir serencamın bahtsız kurbanı olacaktır" (2013, s. 142).

Bu durumda kadının bildiği tek şey kendisine verilen sınırlar içerisinde hareket etmektir. Belirlenen sınırlar içinde nasıl davranacağı zaten kalıp davranışlar olarak bellidir, böyle bir kodlanmışlık durumunda "nesneleştirilen kadın bizzat korunması gereken emanetin bekçisi veya eşiğin sorumlusu olarak görülecektir" (Köysüren, 2013, s. 107). Filmde toplumsal yaşama katılma düzeyi söylemlerin gücü ve kurumsal-erksel pratiklerin uygulanabilirliği ile belirlenirken bizleri feminist kuramcı Judith Butler'in ısrarla vurguladığı, cinsiyetin verilmişlikten ziyade -verilmişliğin yanısıra- "oluşturulan" veya "oluşturulmakta olan" bir "gerçek" olduğu konusuna getirir (2008, s. 66). Cinsiyetin toplumsal inşasında kirlilikten hastalığa, cinsellikten ruhsal sorunlara kadar, kültürel belirlenmişlik boyutu öne çıkar. Yine kadın cinselliğini merkeze alan ahlak anlayışı ve bu konudaki seküler bakış da kültürle ilgilidir. Köysüren'in de vurguladığı üzere "namus kelimesinin yasa (nomas) anlamından türediğini anımsarsak, namusu toplumsal yapılanmada öne çıkaran ve merkeze alan bir toplulukta, ahlaki yasanın belirleyici olarak kadının cinselliğinin ne kadar etkin olduğu görülecektir" (2013, s. 99). Evlendikten sonra altı gün beraber 
olabildiği kocası Mustafa'nın yokluğunda, kayınvalide ve kayınpederinin gözetimine terk edilen Meryem'in toplumsal itibarı muhafaza edeceği namusundan geçecektir. Çünkü kadın şüphesiz erkeğin onurunu sürdürdüğü sürece var olabilir. Bu düzende namus sadece kadın bedenini değil, tüm bireylerin toplumdaki yerlerini, davranışlarını ve arzularını da kontrol altına alan bir toplumsal olgudur. Hatta kültürün maddi ve ruhsal bileşenlerinin içeriği hakkında da ipuçları verir. Ancak bütün güç ve namus ilişkilerinde kadın, namus bakımından hem korunup gözetilendir hem de erkeğin onurunu muhafaza görevine mecbur kılınandır. Namus konusunda bir parçalanma olmadığı veya ona gölge düşmediği sürece güçlü olan ve bu sayede gücü elinde tutan elbette namuslu kadının kocası veya babası olacaktır. Erkek tabi olunan ve güçlü olandır; kadın ise korunan ve tabi olandır. Kısacası kurumlardaki iktidar ilişkilerini üreten, kuran "toplumsal cinsiyet" kadınları tabi olacakları konumlara, erkekleri de hükmedecekleri konumlara getirir (Direk, 2016, s. 18-19).

Var olan rollerin yıkııı tekrarları, bu düzenden bir kaçışın olmadığını ima ederken Meryem hep bekler, umut eder. Sadece birkaç dakika süren tek düze telefon görüşmeleriyle giderilmeye çalışılan özlem ve arzu; evlendiği adamla mutlu olma hayallerini deneyimlemesine asla olanak vermez. Mustafa'nın gelip onu götürmesini beklemek, kıyametin kopmasını, dünyanın toptan değişmesini beklemek gibidir. Geleneğin kurallarının dışına çıkamayan birçok kadın gibi Meryem de hayatın zenginliği ve yaşamın coşkusunun geri çekildiği bu anlarda kendi doğasına yabancılaşmaya mahkûm edilir. Demlendikçe acılaşan hüzün hissi dünyayla arasına koyduğu ve kimseye geçit vermediği sessiz bir sınıra dönüşür.

Filmde sınırların aşııdığı tek yer rüyalardır. Gölün üzerinde yalın ayak sonsuzluğa ve özgürlüğe yürüyen Meryem'in ruhu ve bedeni arasındaki etkileşimi, arzusu ve iradesi arasındaki gerilimi, özgürlüğü ve tutukluluğu arasındaki salınımı seyirciye aktarılırken Meryem'in derinlerde yatan ancak yukarılara çıkması çok da kolay olmayan bir çağrısı seslendirilir: "Ben insan değil miyim?". Meryem'in iç dünyası ve duygularının dışa vurumu, seyirciye sadece rüyalar aracılığıyla değil, filmde kendi kendisiyle baş başa kaldığı odasında ayna karşısındaki görüntüsü ile de aktarılır. Bu sahneler Foucault'nun ayna metaforunu yansıtması açısından oldukça önemlidir. Foucault'ya göre:

"Ayna sonuçta bir ütopyadır; çünkü yeri olmayan yerdir. Aynada kendimi olmadığım yerde görürüm, yüzeyin ardında sanal olarak açılan gerçekdışı bir mekânda görürüm ordayımdır olmadığım yerde, kendi görünürlüğümü bana veren olmadığım yerde, kendime bakmamı 
sağlayan bir tür gölge: ayna ütopyası ... Fakat gerçekten var olduğu ölçüde ve benim bulunduğum yerde bir tür geri dönüş etkisine sahip olduğu ölçüde, aynı zamanda bir heterotopyadır; kendimi orada gördüğümden, bulunduğum yerde olmadığımı aynadan yola çıkarak keşfederim" (2005, s. 297).

Kadınların kişiliklerini açığa çıkarma noktasında birçok eserde son derece önemli rol oynayan ayna metaforu, film anlatısının çözümlenmesinde de oldukça etkin bir araçtır. Filmde aynanın karşısında kendini keşfederek başka bir kimlikle yeniden farklı bir role bürünebilen öznenin, Meryem'in, kendi bedeniyle, kendi cinselliğiyle ve kendi bireyselliğiyle yaşadığı "epifanik" (uyanış) anlar seyirciye ayna metaforu aracılığıyla aktarılır. Bu anda arzuların üzerindeki örtüler kalkar, çelişkiler ve çatışmalar ortaya çıkar. Değişim ve dönüşümün yaşandığı bu anlar Meryem'in bir birey olarak "kendi bilincinin efendisi olması"nı olanaklı kılar. Aynadaki bu görüntü Meryem'in daha önce fark etmediği yeni birisinin görüntüsüdür. "Kendini tanı aynası" olarak adlandırılan bu ayna metaforunu Melchior-Bonnet şöyle aktarır:

"Hem içe dönük hem de yansıtmacı ikili (iki katmanlı) bir bakışla birey, kendisini özne olarak tanımlayabilir. "Kendini tanı aynasında kendini (benliğini) incelemek, kendi imgesini diğerlerinin aynasında oluşturduğu için, öteki bakışların altında kendisi için bir temsile dönüşürken aynı zamanda kendi bilincinin efendisi olmasını sağlayarak bireye kendini tanıma şansı verir. Kendini görmek ve görünmek, kendini bilmek ve bilinmek- bunlar birbirine bağlı eylemlerdir" (2007, s. 156).

Ataerkilliğin kuşattığı varoluş alanında birçok etmen tarafından örselenen, yıpratılan benlik alanında Meryem, birçok kadın gibi farkındalıklarını ve deneyimlerini ifade etmek, fark edilmek, kabul edilmek ister. Fakat ne yazık ki kadınlık ve erkekliğin anlamı toplumsal ihtiyaca göre üretilir. Kadınları kontrol altına alan eski düzenin yerel adetleri film boyunca bütün detaylarıyla irdelenirken, rüyalar dışarıdan bir sesle kesintiye uğratıır. Kayınvalidesinin ev içinde sürekli gözetim altında tuttuğu Meryem ne yatmasını bilir ne de kalkmasını. "Canı hep yatmak ister, ne olacak" cümleleriyle suçlanan ya da "kapat şu televizyonu yat da uyu" uyarılarıyla kısıtlanan; ev dışında ise "Meryem, ne zaman gidiyon?" (Taşdiken, 2013) sorusu ile hemcinsleri tarafından sürekli baskılanan genç kadının kendisinin ne istediğinin hiçbir önemi yoktur.

Filmde kültürel hafızadan beslenen mitlerin, efsanelerin, ritüellerin üzerinde durulurken toplumsal hafızanın da bütünüyle unutulmayacağının altı çizilir. Tıpkı Çınar'ın da dillendirdiği gibi, "mitler biçim değiştirse bile ritüelleri bütünüyle toplumdan kazıp atmak mümkün değildir. Dolayısıyla ritüeller, 
bir tür anlam öbeklerinin saklandığı kalıplardır. Bu kalıpların yeniden güncellenmesiyle, eskiyle bağlantı kurulur ve şimdi de yeni boyutlar yakalanır" (2010, s. 25). Filmde Meryem'in kayınvalidesi tarafından Eflatun Pınar'a götürülüp soğuk suya sokulduğu ve ardından hastalandığı sahne yukarıda aktarılan cümlelerin anlamını yüklenen en güzel sahnelerden biridir. Mustafa'nın ataerkil ailesiyle, geleneksel yapının kendisine dayattığı yaşamı kabullenen Meryem, kayınvalidesinin götürdüğü bu pınarda "burada abdest alanın çocuğu olurmuş; senin de çocuğun olsaydı, kocan duramaz gelirdi" sözleriyle geçmiş ve bugünün gel-git aralığında baskılanır, yargılanır kısacası ikincilleştirilerek sınır dışına itilir.

Geleneksel algı tüm bu ritüelleri güncellerken kadının nasıl okunması gerektiği algısını da yaratır. İrigarary'in vurguladığı üzere; "kadının doğası özellikle annelik açısından düşünülürse, namus eksenli algı anneliği kutsadığı için diğer boyutlarından çaldığı kadını, doğal anaç yönüyle baş başa bırakarak cinsiyeti bir görev boyuna kilitleyecektir. Onun rolü anne olmak olacaktır. Böylece edilgenlik onun için kesilen bir elbisedir" (2006, s. 47). Deniz Kantiyoti'nin de vurguladığı üzere "yeni evlenen gelin yaş-cinsiyet hiyerarşisinde en alttadır... Gelinin konumu, erkek çocuk doğurabilmesi ve yaşının ilerlemesiyle yükselir. Oğulları eve gelin getirdiğinde saygınlığının doruğuna ulaşır" (Kandiyoti, 2007, s. 58). İşte bu yüzden feminist çalışmalar tüm bu ilişkilerin kurumsallaştı̆̆ı aile yapısına odaklanır. Sözü edilen yapı Connell'e göre "... toplumun temeli olmanın ötesinde, onun en karmaşık ürünlerinden biridir. Aileye dair basit hiçbir şey yoktur. Ailenin içi, tıpkı jeolojik katmanlar gibi birbiri üzerine yığılmış çok katmanlı ilişkiler sahnesidir. Başka hiçbir kurumda ilişkiler, zaman içinde böylesine yaygın; temas esnasında böylesine yoğun; ekonomi, duygu, iktidar ve direniş örgüleri açısından böylesine sıkı değildir (1998, s. 167-168). Böyle bir yapıda Meryem'in kimliğinin oluşması imkânsızlaşacak ve kadın "ataerkil yapının veya söylemin dışında tutulmuş olacaktır" (Butler, 2005, s. 133).

Film boyunca estetiğin sadece nesnesi konumuna indirgenen genç bir kadının sinsice insan kimliğinin ve benliğinin parçalanışına tanıklık eder seyirci. Ataerkil ideoloji tarafından üretilen toplumsal cinsiyet rollerinin gölgesinde her geçen gün daha da sessizleşir Meryem. Çünkü egemen kültürde kadınlara etkin ve özerk bir özne olma hakkı tanınmaz. Fatmagül Berktay'ın Kadın Olmak, Yaşamak, Yazmak adlı eserinde de vurguladığı üzere "Bu kültürde kadını simgeleyen, temsil eden olması çok güç görünür. Çünkü kadının kendisi bir simgedir. Simgeleme, nesneleri adlandırma, tanımlama gücü geleneksel olarak erkeğin elinde olunca, kadın da simgelenen bir nesneye dönüşür. Egemen kültürün özündeki bu edilgen simge ve etkin simgeleyen ayrımı eşitsizliğin baskının ve iktidarın önemli bir ideolojik 
göstergesidir" (1998, s. 9). Berktay'ın bu düşüncesi Jale Parla ve Sibel Irzık tarafından aşağıdaki cümlelerle desteklenir:

"... ataerkil ideolojiler kadınların var oluşunu mahremiyet, sessizlik, doğallık, gizem gibi kavramlarla tanımlayarak dil ötesi, daha doğrusu dil öncesi bir alana hapseder, kamusalın karşıtı olarak kurgular. Bu kurgu, kadınların sesleri, kimlikleri, bedenleri üzerinde uygulanan denetimin en önemli dayanaklarından biridir, çünkü kadınların kamusal alanda kendi varlıklarını görünür, duyulur kıldıkları her durumda, kendi doğalarına aykırı bir şey yapmakta oldukları uygunsuz bir biçimde dikkat çekerek kendileri hakkındaki sözleri kışkırttıkları, kendilerini açıp sergiledikleri için çirkinleşip rezil oldukları kendilerine sürekli aktarılır" (2004, s. 7).

Filmde kavanozdaki çakıl taşlarıyla ölçülüp biçilen zaman, İstanbul ve Mustafa'ya kavuşma umudu, telefonda ailesi tarafından zorla evlendirildiğini itiraf eden Mustafa'nın Meryem'i sevmediğini ve boşanmak istediğini ifade ettiği cümleleriyle parçalanır. Meryem için bu durumdaki yaşam "sadece ölmemektir". Aşktan, düşlerden, umuttan bahsedilemez. Fatmagül Berktay'ın aşağıdaki cümlelerle ifade ettiği gibi bu koşullarda aşk, insanoğlu ve insankızı için artık imkânsızdır:

\begin{abstract}
"Hayatı bir tiyatro sahnesi gibi yaşadığımız, 'kendi kendimizin gözetleme kulesi' olduğumuz bu görünümler dünyasında, düş kurarız, 'gelecek biriktiririz' durmadan ama düşleri yaşamaya gelince korkarız; ya da onlar büyülerini yitirir. Uyuyan güzel'in 'kendisi değil, masalını sever Prens'. Çünkü, masaldan sonrası nasıldır, bir kadın sevmek nasıldır, ona öğretilmemiştir: ... Üstelik eşit olmayan bütün ilişkilerin çürüme ve nefret koktuğu koşullarda, öğreneceği de yoktur ve onun içindir ki dünyanın bütün hatlarında aşk imkânsızdır" (1998, s. 20).
\end{abstract}

Filmin sonunda Beyşehir'den İstanbul'a gönderilen Meryem, yaşadığı mekânın yersiz yurtsuzu genç bir kadındır. Düşleri, umutları çalınmış yaşanılan ya da dayatılan tüm sorumluluklar birey olarak var olabilmenin imkânsızlı̆ıını hafızasına kazımıştır. Hayatın zenginliği ve yaşamın coşkusunun geri çekildiği bu anlarda, kendi varoluş sorunu ile baş başa, yaşadığı çaresizlik ve yalnızlık duvarlarıyla örülü coğrafyasında, "gidilmeyen yolun yolcusu"dur artık Meryem, gönderildiği İstanbul sokaklarında.

\title{
SONUÇ
}

İnsanların kaderleri gündelik yaşamda yer alır (Özdemir, 2005, s. 107). Gündelik hayatı inceleme alanı içine alan sanat yapıtı sinema ise içinde yaşadığımız toplumu anlamlandırmaya, dönüştürmeye çalışır. Filmleriyle Türk sinemasında yeni bir duyarlılık evreni oluşturmaya çalışan Atalay Taşdiken'in Meryem filmi de gündelik hayatın içerisinde gizlenen kıyıda köşede kalmış pek çok ayrıntıyı bizlere 
yansıtarak içinde bulunduğumuz toplumsal yapıyı çözümleyebilecek ve açıklayabilecek bilginin kaynağına ulaşmamızı sağlar.

Atalay Taşdiken'in içinde bulunduğumuz toplumun olumsuzluklarından ve sorunlu ilişki biçimlerinden beslenerek kurguladığı Meryem karakteri aslında daha adını söyleyecek kadar bile büyümeden sandıklar dolusu çeyize sahip çıkması beklenen kız çocukların, çocukken gelin, gençken yaşlı gibi hisseden genç kadınların, sokakta oynarken birdenbire kendini bir adamın koynunda bulan, bedenini tanımadan başka bir bedene bağışlayan, ruhunu özgürleştirmek şöyle dursun, tutsaklığı kader diye algılayıp onu bile sevmeye zorlanan sayısız kadının, Meryem'in yansımasıdır.

Unutulmamalıdır ki insanın varoluş alanı diğer insanlarla paylaştığı dünyasıdır. Diğer insanlarla paylaştığımız bu dünyada diğerlerinin özgürlüğünü yok saymamız mümkün değildir. Özgürlük, ancak herkesin özgürlüğünün tanındığı bir dünyada gerçekleşebilir. Aksi takdirde estetiğin sadece nesnesi konumuna indirgenen Meryem'lerin sinsice insan kimliği, benliği parçalanacaktır.

\section{EXTENDED ABSTRACT}

Gender, an identity constituted in time and instituted in an exterior space through a stylized repetition of acts, can be explained well in the famous words of Simone de Beauvoir, "one is not born, but rather becomes, a woman." As it is stated "gender" is not something we are born with, and not something we have, but something we "do" or something we "perform". It is something "imposed" as a way of living and it is perceived as a fact by corparating in to our culture, traditions and daily life activities. But this inequality is often part of traditions rooted in cultural values deserving of respect. Social relations are generally gender-oriented.

Being a man and a woman is not just an innate feature, but an identity created by society. The psyclological characteristics and behaviours that distinguish male and female are the result not of biology but of socialisation of sex-appropriate responses and behaviours learned. That is why women's oppression is the result of a historical development and cultural phenomena of societies. The societies' views concerning sex appropriate behaviour passing down from generation to generation are perceived as natural. All meanings and symbols attributed to gender creates an ordered world encompasses social and class relations with gender hierarchy. The sex/gender system, which plays an important role in shaping the thoughts of an individual, becomes "factual" when incorporated into people's habits and 
cultures. These characteristics defined in the context of the gender continue throughout life and individual can never be "me". Therefore a woman without having any self-confidence and selfawareness acts according to thoughts of male dominant culture and sees herself through man's eyes. So man becomes the oppressor and the woman becomes the oppressed. This disposition between male nobility and female subjection consistently feeds the social relations.

In this study, the movie Meryem based on a true story of a woman from Beyşehir is taken into consideration as a successful example in the context of gender. Supported by TR Ministry of Culture the movie Meryem was scripted and directed by Atalay Taşdiken. He, Beyşehir born director and lover of Beyşehir, with the definition of femininity in his films brings something important or interesting to our attention by questioning the fact related with the situation and the condition of women in society. In the selected film, we will examine the roles of the society we live in and the roles that women held in the Anatolian countryside, in Beyşehir, by examining the feminine situations shaped by customs and dialogue and the patriarchal marriage system that approves the hierarchy. Though the theme of the film seems to be one of the ordinary stories of the ordinary people, it is not only one of the stories that Meryem has lived but also it is the hurtful drama that has been lived for hundreds of years in Anatolia. In Anatolia, many of whose areas constructed with tradition, custom, and religious belief, patriarchal principles imprison women in a limited life that prevents them from participating in relations of production and establishing environmental communication. In this hierarchical system, which is nourished by a natural continuity based on the past; the women seeking their place within society socialized into roles such as fresh bride, young woman, daughter-in-law, sister-in-law and mother-inlaw. These are the important roles that shape their way of living.

In this study, Atalay Taşdiken, the director of the film, reflecting the position of women and presenting the changing sides of the world shaped by the relationship between men and women creates a new approach to sensitivity in Turkish movie. In his films he attempts to present the problems of the individuals from his own perspective. He takes the psychosocial approach to display especially women in their own geography (environment) surrounded by the walls of desperation and loneliness. Taşdiken, in his films, with all the reflections of depth psychology, discusses the problems of women's existence, their helplessness against harsh living conditions and realities, their exhaustion and problems resulting from the patriarchal patterns of control, oppression and repression. In the movie Meryem, the main 
concern of this study, with numerous status dimensions related to education, physical and mental disabilities, culture, religion, marital status, parenthood, citizenship, politics, cultural standards of physical attractiveness and social manners are taken into consideration in order to attract attention to a system of social structures and practices. Taşdiken questions the status quo which has been a standard part of sociological practices by noting that patriarchy is related to institutionalized control, and not merely people's individual sexism.

Consequently, every piece of writing or work of art -whether a poetry, an essay, a criticism or a film scenario- is a message that conveys news and greetings from someone who can think and question to those who can also think and question. They lead us to thinking and questioning. The movie Meryem is also "a call" for each of us to step back and examine gender from a new perspective. So, in the light of feminist film criticism, the aim of this study is, by raising consciousness about gender, to mirror women's difficult life in Anatolia or anywhere else we have never been before. This is the story of everyone, every single woman who cannot express their own feelings. To end inequality and discrimination we have to translate words into deeds and we have to say it loud and clear that human rights are universal and gender equality as an expression of those rights is universal as well; so women's rights are human rights. No philosophical, political, religious or other reasons can justify the violation of these fundamental ideals and this is the type of globalization that we have to value to the utmost.

\section{KAYNAKÇA}

Abisel, N. (1999). Popüler sinema ve türler. İstanbul: Alan Yayıncılık.

Bayhan, V. (2013). Beden sosyolojisi ve toplumsal cinsiyet. Doğu-Batı Düşünce Dergisi, 63(1), 147-164.

Belkaya, A. G. (2001). Film çözümlemesinde temel yaklaşımlar. İstanbul: Der Yayınları.

Benedick, R. (1998). Kültür örüntüleri. (M. Topal, Çev.) Ankara: Öteki Yayınları.

Berktay, F. (1998). Kadın olmak, yaşamak, yazmak, İstanbul: Pencere Yayınları.

Butler, J. (2005). Iktidarın psişik yaşamı. (F. Tütüncü, Çev.) İstanbul: Ayrıntı Yayınları.

Butler, J. (2008). Cinsiyet belası: feminizm ve kimliğin alt üst edilmesi. (B. Ertür, Çev.) İstanbul: Metis Yayınları.

Büker, S., \& Topçu, G. (2010). Sinema: tarih-kuram-eleştiri. İstanbul: Kırmızı Kedi Yayınevi.

Connell, R. W. (1998). Toplumsal cinsiyet ve iktidar-toplum, kişi ve cinsel politika. (C. Soydemir, Çev.) İstanbul: Ayrıntı Yayınları. 
Çınar, A. (2010). Feminist theology: the philosophial and religious origins of problem of femininity. Journal of Alternative Perspectives in Human Sciences, 1(1), 21-29.

Direk, Z. (2016). Cinsiyeti yazmak. İstanbul: Yapı Kredi Yayınları.

Eagleton, T. (2004). Kuramdan sonra. (U. Arabacı, Çev.) İstanbul: Literatür Yayınları.

Elmacı, T. (2011). Taşrada gündelik hayatın ideolojisinin Vaviven ve Süt filmleri perspektifinden okunması. Selçuk iletişim Dergisi, 7(1), 161-173.

Fine, C. (2011). Toplumsal cinsiyet yanılsaması. (K. Tanrıyar, Çev.) İstanbul: Sel Yayıncılık.

Foucault, M. (2005). Başka mekanlara dair özne ve iktidar içinde. (I. Ergüden, Çev.) İstanbul: Ayrıntı Yayınları.

Güçhan, G. (2004). Toplumsal değişme ve Türk sineması. Ankara: Imge Yayınları.

Güvenç, B. (1999). Insan ve kültür. Ankara: Remzi Kitabevi.

İrigaray, L. (2006). Ben sen biz farklılık kültürüne doğru. (S. Büyükdüvenci, \& N. Tutal, Çev.) İstanbul: İmge Yayınevi.

Kandiyoti, D. (2007). Cariyeler, bacılar, yurttaşlar kimlikler ve toplumsal dönüşümler. İstanbul: Metis yayınları.

Köysüren, A. Ç. (2013). Kültürel ve dini algıda toplumsal cinsiyet. Ankara: Sentez Yayıncllık.

Lefebvr, H. (2007). Modern dünyada gündelik hayat. (I. Gürbüz, Çev.) İstanbul: Metis Yayınları.

Melchior-Bonnet, S. (2007). Aynanın tarihi. (i. Yerguz, Çev.) Ankara: Dost Kitapevi.

Özdemir, Ö. M. (2005). Dünyayı keşfetmek üstüne: dokü-safarilerle seyr-i alem. Sanat Dünyamız(94), 106-112.

Özden, Z. (2000). Film eleştirisi, film eleştirisinde temel yaklaşımlar ve tür filmi eleştirisi. İstanbul: Afa Yayınları.

Parla, J., \& Irzık, S. (2004). Kadınlar dile düşünce: edebiyat ve toplumsal cinsiyet. İstanbul: iletişim Yayınları.

Simelik, A. (1998). Feminist sinema ve film teorisi ve ayna çatladı. İstanbul: Agora Kitaplığı.

Sözer, Ö. (1993). Kadın ve benzeri bir kadın ütopisi. İstanbul: Varlık Yayınları.

Süllü, N. (1988). Sinemada feminist eleştiri. Yayınlanmamış Yüksek Lisans Tezi. Eskişehir: Anadolu Üniversitesi.

Tan, E. M. (1979). Kadın: ekonomik yaşamı ve eğitimi. Ankara: Iş̧ Bankası Kültür Yayınları.

Taşdiken, A. (Yöneten). (2013). Meryem [Sinema Filmi].

Timisi, N. (2011). Sinemaya feminist müdahale: Laura Mulvey'de psikanalitik seyirciden teknolojik seyirciye. M. İri (Dü.) içinde, Sinema Araştırmaları - Kuramlar, Kavramlar, Yaklaşımlar (s. 161-186). İstanbul: Derin Yayınları.

Turner, B. S. (1996). The body\&society-explorations in social theory, culture and society. London: Sage Publications. 